\title{
A Matemática Escolar da Escola Primária da Década de 1940
}

\author{
Primary School Mathematics in the 40s
}

\author{
Laura Isabel Marques Vasconcelos de Almeida*a; Neuza Bertoni Pinto ${ }^{\mathrm{b}}$ \\ ${ }^{a}$ Universidade de Cuiabá. MT, Brasil. \\ bontifícia Universidade Católica do Paraná, Programa de Pós-Graduação Stricto Sensu em Educação. MT, Brasil. \\ *E-mail: lauraisabel@terra.com.br \\ Recebido em: 19/08/15. Aprovado em: 04/11/15
}

\begin{abstract}
Resumo
São raros os estudos voltados à história da matemática escolar, sobretudo os que buscam compreender como esse componente curricular favoreceu a permanência ou a transformação da cultura escolar da escola primária. O presente estudo tem como objetivo compreender como se apresentava a matemática escolar do ensino primário, na década de 1940, em duas escolas primárias do estado de Mato Grosso. A partir de um olhar minucioso aos conteúdos matemáticos prescritos e às formas como estes eram apropriados nas práticas escolares da escola primária, o estudo, orientado na perspectiva da história cultural, identifica mecanismos e lógicas utilizados pelos sujeitos na preservação da coerência simbólica da cultura escolar.
\end{abstract}

Palavras-chave: Escola Primária. História da Matemática Escolar. Cultura Escolar.

\begin{abstract}
Studies focused on the history of school mathematics are rare, especially those who seek to understand how this curricular component favored the school culture of primary school retention or transformation. This article aims at understanding how they had school mathematics in primary education, in the 1940s, in two primary schools in Mato Grosso state. From a detailed analysis of the prescribed mathematical content and how the same were appropriate in primary school practice, the study, guided by the cultural history perspective, identifies mechanisms and logics used by the subjects in preserving the symbolic coherence of school culture.
\end{abstract}

Keywords: Primary School. Mathematics School History; School Culture.

\section{Introdução}

A história mais recente da educação brasileira vem apontando aspectos singulares da escola primária, em especial das disciplinas escolares que em tempos passados compunham o currículo desse segmento de ensino. Entretanto, ainda são raros os estudos voltados à história da matemática escolar, sobretudo os que buscam compreender como esse componente curricular favoreceu a permanência ou a transformação da cultura escolar da escola primária.

Ao tratar da história das disciplinas escolares, Chervel (1990) enfatiza que a escola é um espaço criativo de produção e não de transposição de saberes advindo das ciências. Nela, as disciplinas escolares ocupam um espaço relevante na concretização das reais finalidades do projeto educativo. Não se trata de uma história que concebe o passado como ingrediente explicativo do presente, mas que possibilita, aos professores, de modo particular aos das séries iniciais do atual ensino fundamental, o conhecimento das representações do passado e, nele, o papel determinante que a matemática escolar cumpriu na escolarização da população.

Valente (2004) destacou a crítica que vem sendo travada em torno do conceito de transposição didática, ao considerar que as disciplinas escolares, enquanto criações espontâneas da escola, não resultam de uma adaptação dos saberes oriundos das ciências. O autor concorda com a afirmação de Chervel (1990, p.207), de que

toda disciplina escolar representa uma combinação, em proporções variáveis, de um ensino de exposição, de exercícios de práticas de incitação e de motivação e de um aparato de testes, provas e exames que lhes dão legitimidade e conformação.

Considerando o "modelo chevallardiano" inviável para a história da educação matemática, Valente (2004, p.79) afirma que

a grande contribuição da Nova História das Ciências, para o entendimento dos significados dos saberes escolares, situa-se no alerta de que para ser estudado, todo saber escolar deve levar em conta a reconstrução dos conceitos específicos de sua produção e apropriação.

A partir dessas proposições, o campo da história da matemática escolar, ao dar visibilidade aos vestígios deixados na produção escolar, apresenta-se como um terreno fértil para legitimar o papel desse componente curricular na consecução da escolarização elementar.

O presente estudo tem como objetivo compreender como se apresentava a matemática escolar do ensino primário, na década de 1940, em duas escolas primárias do estado de Mato Grosso. A partir de um olhar minucioso aos conteúdos matemáticos prescritos e às formas como estes 
eram apropriados nas práticas escolares da escola primária, o estudo, orientado na perspectiva da história cultural, identifica mecanismos e lógicas utilizados pelos sujeitos na preservação da coerência simbólica da cultura escolar.

Considerando a relevância da produção escolar para a compreensão da história da matemática escolar da escola primária, o estudo vale-se dos conceitos da historiografia francesa, como o da cultura escolar (JULIA, 2001) e o de disciplina escolar (CHERVEL, 1990).

As fontes foram constituídas com documentos escolares da década de 1940, localizados no Arquivo da Escola Plácido de Castro, da cidade de Diamantino/MT, contendo registros das disciplinas que compunham o currículo escolar da escola primária. Tratam-se dos documentos: "Registro Geral do Estabelecimento", do ano de 1941, da Escola Primária Urbana Masculina e Feminina ${ }^{1}$ (MATO GROSSO, 1941) e do "Registro Geral do Estabelecimento", do ano de 1943, do Externato Santa Teresinha (MATO GROSSO, 1943b), ambas as instituições sediadas naquela cidade e que na década de 1940 foram o embrião da atual Escola Estadual Plácido de Castro. Também foram consultados dois documentos oficiais da educação elementar de Mato Grosso, em vigor na década de 1940: o "Regulamento da Instrução Pública da Escola Primária" de 1927 (MATO GROSSO, 1927) e o "Relatório da Diretoria Geral da Instrução Pública" (MATO GROSSO, 1943a), ambos localizados no Arquivo Público de Mato Grosso - APMT.

Ao reconhecer o valor de um saber histórico, capaz de dirimir mitos, preconceitos e desconhecimentos acerca do passado da matemática escolar da escola primária, o estudo busca compreender como essa disciplina articulou-se, nas práticas escolares, no auge do período ditatorial do governo Vargas.

\section{Desenvolvimento}

\subsection{Da história da escola primária à história da matemática escolar no Brasil}

As pesquisas que tratam da história da escola primária brasileira vêm apontando o papel determinante da institucionalização dos grupos escolares, implantados no Brasil no início do período republicano, para a constituição de um modelo republicano de educação cuja característica principal foi permitir a passagem de uma escolarização individualizada e fragmentada para uma prática escolar racionalizada e hierarquizada, proposta educativa considerada relevante na consolidação em nosso país do ensino laico, estatal e gratuito (VIDAL, 2006).

O balanço desses estudos, realizado por Souza e Faria Filho (2006), destaca que a história dos grupos escolares, ao encarnar o sentido da escola primária no país, acaba confundindo-se com a própria história da escola primária. Enquanto um ícone do período republicano, os grupos escolares configuraram-se como uma organização escolar apropriada para a socialização dos valores republicanos, um símbolo da modernização da escola pública a serviço de um projeto civilizador que deixou marcas profundas na cultura escolar da escola primária brasileira. Os autores observam que um grande desafio enfrentado pelos pesquisadores da história dos grupos escolares tem sido o de desvendar a cultura escolar, considerando, no jogo das permanências e transformações, a estabilidade das práticas escolares.

Recentes estudos históricos das disciplinas escolares têm procurado analisar essa questão, na medida em que problematizam métodos e conteúdos de ensino dos componentes curriculares, o que tem contribuído com análises fecundas de como os ideários e as concepções foram apropriados por professores e alunos nas práticas escolares, em diferentes períodos históricos (OLIVEIRA; RANZI, 2003).

Se, por um lado, as fontes historiadoras das pesquisas da constituição da escola primária, especialmente os documentos oficiais, auxiliam no entendimento das transformações da distribuição e consolidação das disciplinas escolares, por outro as fontes documentais utilizadas pelos historiadores das disciplinas escolares, em geral as produzidas pelos agentes escolares, oferecem à história da escola primária nova compreensão de como, ao longo de um passado histórico, foi sedimentada a cultura escolar da escola primária.

Como observa Julia (2001), a cultura escolar é um construto que molda as ações educativas no interior da escola. Nessa construção, normas e práticas são legitimadas pelas ações e participação dos sujeitos educativos, envolvendo, no caso das disciplinas escolares, professor e aluno no processo de conformação ou transformação de uma tradição escolar.

As recentes investigações da matemática escolar mostram que, no Brasil do Império ao final da Primeira República, a disciplina Matemática, na época denominada Aritmética, passou por uma série de transformações, ajustando-se às prescrições da política educacional vigente. Além de mudanças no rol de conteúdos programáticos, os métodos de ensino e os livros didáticos utilizados foram determinantes na definição das reais finalidades da matemática escolar da escola primária.

O estudo de Silva (2008), ao tratar historicamente da presença da matemática na formação do professor do ensino primário no estado de São Paulo, no período de 1890 a 1930, mostra os vínculos entre as mudanças ocorridas nos programas das então escolas normais e a matemática vigente na escola primária, especialmente em relação aos métodos de

1 A Escola Urbana Masculina e Feminina e o Colégio Externato Santa Terezinha eram duas instituições diferentes, a primeira pública e a segunda particular. Foram constituídas na mesma época, funcionaram durante o mesmo tempo e ambas extintas em 1948. Com a extinção dessas duas escolas, os alunos se juntaram e passaram a constituir a Escola Reunida Major Caetano, que funcionou até 1961. Posteriormente constituiu o Grupo Escolar Caetano Dias, que funcionou até 1973, mais tarde reorganizado e denominado Escola Estadual Plácido de Castro. 
ensino trabalhados nos cursos de formação e aqueles vigentes no ensino e na aprendizagem da matemática elementar.

Valendo-se da legislação, relatórios de inspetores e periódicos em circulação na época, como a Revista do Ensino, a autora mostra que o maior impacto ocorrido nesse período, em relação aos métodos, deu-se na passagem do ensino mútuo para o método intuitivo. Um fator importante dessa mudança, apontado pelo estudo, foi a introdução das Cartas de Parker ${ }^{2}$ na matemática escolar da escola primária paulista, no início do século XIX, material didático amplamente utilizado nos então grupos escolares existentes no país.

$\mathrm{Na}$ história da matemática escolar no Brasil, Valente (1999a) destaca o papel preponderante do livro didático na constituição da matemática escolar. Livros como os de Alpoim que marcaram, no período imperial, o caráter prático da matemática a serviço da formação de bombeiros e marinheiros, os livros de Belidor e Bézout que, na Primeira República, ao contrário de lições a serem memorizadas, introduziram exercícios para os alunos, além dos $\mathrm{FICS}^{3}$, que foram amplamente utilizados pelos professores da escola primária brasileira.

O estudo de Valente (1999a) ressalta o papel desempenhado pelo livro didático de Aritmética como ordenador da cultura escolar, seja reforçando ou distanciando-se da cultura clássica literária que marcou a educação republicana. Servindo de bússola ao professor, os livros apresentados por Valente, além de informar o rol de conteúdos programáticos, sinalizavam elementos didático-pedagógicos de como ensinar, indicando, mesmo de forma implícita, o método a ser seguido.

Segundo o autor, a primeira Aritmética destinada à escola primária brasileira foi a Aritmética de Cândido Baptista Oliveira, com edições em 1832, 1842 e 1863. O livro, escrito para professores, apresenta uma pedagogia específica, “as pranchas didáticas", que continham exemplos de cálculos numéricos a serem copiados pelos alunos (VALENTE, 1999a). Além das quatro operações com números inteiros, o livro apresentava um programa mais amplo para a escola primária, incluindo números fracionários, decimais, complexos, proporções, regra de três, raiz quadrada e introduzia também a metrologia que, segundo Valente, atesta o pioneirismo da obra ao traduzir o novo sistema de pesos e medidas francês.

A Aritmética de Oliveira configurou-se como um material didático centrado na memorização, apropriado para o ensino mútuo, método que marcou a matemática escolar tradicional no Brasil, durante a Primeira República.

A julgar pelas edições e pela divulgação da Aritmética de Oliveira em partes pela imprensa, é razoável supor que tenha havido um período de utilização dessa que seria a primeira 'aritmética nacional' nas escolas mútuas em substituição aos textos estrangeiros. A prática de construção dos murais teria, assim, ficado facilitada com o texto de Oliveira (VALENTE, 1999b, p.278).

Para Valente (1999a), outra obra que teve uma longa permanência nas práticas pedagógicas da escola primária foi a Aritmética Elementar Ilustrada, de Antonio Trajano. As obras de Trajano, destinadas à escola primária e secundária, foram verdadeiros best- sellers, possivelmente por inovarem na forma didática de apresentação dos conteúdos matemáticos.

O grande diferencial dos livros de Trajano situa-se na forma didática do texto. A teoria é sempre posta por meio de exemplos numéricos, seguidos de exemplos resolvidos, com explicação passo a passo do que o aluno deverá realizar. Seguem os exemplos, conjuntos de exercícios com resposta final já dada. Há também exercícios sem respostas. Ao final do livro, o autor anuncia; Revista Geral-Problemas para o exame (VALENTE, 1999a, p.165).

Os estudos de Bittencourt (1993) já apontavam que Antonio Trajano produziu livros de Matemática para as escolas primárias e secundárias e com a premiação da obra Aritmética elementar ilustrada, na exposição de 1883 do Rio de Janeiro, tornou-se um autor nacionalmente conhecido. Segundo a autora, este livro teve a primeira edição em 1879 e a $136^{\text {a }}$ edição foi posta a circular em 1958. Para o ensino secundário, Trajano escreveu Aritmética Progressiva, com $1^{\mathrm{a}}$ edição em 1880.

$\mathrm{Na}$ literatura educacional, Backheuser (1946) ${ }^{4}$ afirmava que o ensino da Aritmética ${ }^{5}$ da escola primária era herdeiro de variadas influências estrangeiras e que, durante meio século, apresentou uma lenta evolução. Segundo o autor, a influência francesa predominou por mais de cinqüenta anos e a matemática escolar baseava-se essencialmente na memória. $\mathrm{O}$ autor caracterizava o ensino desse período pelo seu "feitio decorador", que também perpassava as demais disciplinas do então curso primário até o advento da República em 1889, momento em que a didática dessa matéria (como era denominada uma disciplina escolar) passou a fundamentar-se

2 Material didático elaborado por Francis Wayland Parker (1837-1902), recomendado ao professorado paulista pelos gestores da Revista de Ensino, nas edições de 1902/1903 (SILVA, 2008).

3 Os livros por FIC - Freires de l'Instruction Chrètienne - foram livros didáticos originários da Congregação dos Frères de Ploërmel que seguiam os moldes do ensino tradicional. Raja Gablagia traduziu inúmeros deles. Expressavam a força do ensino em separado de cada ramo da matemática, um apoio didático-pedagógico de sobrevivência às inovações (VALENTE, 1999a, 2003).

4 Everardo Backheuser, professor de Mineralogia e Geologia na Escola Politécnica e presidente da Confederação Católica Brasileira de Educação e Presidente da Comissão do Ensino Primário após 1930. Autor de inúmeros livros didáticos, empenhou-se em encontrar uma terceira via entre o tradicionalismo e o ideário da Escola Nova.

5 Contas era antigamente o nome da aritmética rudimentar. Alguns ainda a chamam de cálculo, dando-lhe duas designações: de contas (ou cálculo), para os rudimentos da aritmética do curso primário, e de Aritmética, para a ciência propriamente dita, estudada nos cursos secundários; havia a vantagem de fixar com bastante nitidez a linha de demarcação da didática primária e da didática secundária dessa disciplina. É o que ainda se dá hoje em dia na língua alemã: Rechenunterricht, que se traduz ao pé da letra por ensino de contas, é o vocábulo que designa o estudo da Aritmética no curso primário (BACKHEUSER,1946). 
no raciocínio.

Essa fase, denominada por Backheuser de teorismo "flou”, preocupada em formar cientistas, em valorizar "uma educação para cientistas" e não uma "educação pela ciência", foi, segundo o autor citado, mais nociva que o mecanicismo da fase anterior, pois, apesar de ser tão prejudicial quanto a precedente, deixava no aluno uma "petulante impressão de alto saber, ao passo que os 'decoradores' sempre se caracterizaram por muita modéstia e muita timidez em assuntos matemáticos" (BACKHEUSER, 1946).

Uma terceira fase, segundo o autor designada de influência norte-americana, era uma justa reação aos exageros do teorismo, em que "volta-se a querer a prática" (BACKHEUSER, 1946).

Para Pinto (2008), uma tentativa de intervir na tradição aritmética, demasiadamente enciclopédica e utilitarista das fases apontadas por Backheuser, já havia sido apresentada por Rui Barbosa na Câmara dos Deputados, em 1883 - um extenso relatório propondo uma nova programação para o curso primário, inspirado na obra de Allison Norman Calkins, Primary Object Lessons, mais tarde traduzido por ele como Lições de Coisas. Esse método (intuitivo) era utilizado no Colégio Progresso, no Rio de Janeiro, pela professora norteamericana Eleanor Leslie, o que, face às condições gerais do trabalho escolar da época, representou uma revolução (PINTO, 2008).

Apesar de eleger o cálculo, ensinado exclusivamente por meio de combinações e aplicações concretas, como um dos elementos fundamentais para a formação do indivíduo, exaltar o cálculo mental e os problemas concretos, condenar a decoração da tabuada, a proposta de Rui Barbosa foi mal compreendida e não obteve aprovação da Câmara. A Aritmética da escola primária, nesse período, prosseguiu em sua linha positivista (PINTO, 2008).

A obra de Backheuser indica que, a partir de 1930, aumentou a polêmica em torno do método de ensino da Aritmética do curso primário. Advogando a favor do ensino intuitivo, um ensino da Aritmética por meio de jogos coletivos, de problemas resolvidos em cooperação, seguindo uma concepção contrária àquela proveniente do grande reformador norte-americano John Dewey, o autor faz críticas severas à vertente norte-americana da escola nova, muito divulgada nesse período no Brasil. Backheuser alegava que a visão utilitarista, disseminada pelo reformador norte-americano, acabou por deturpar as nobres finalidades da educação integral (PINTO, 2008).

Com a aura dos grupos escolares - símbolo da escola primária de excelência -, o método intuitivo, defendido anteriormente por Rui Barbosa, foi amplamente disseminado nas Escolas Normais, na década de 1930, consolidandose nas práticas de ensino das professoras normalistas cuidadosamente preparadas para realizar, na escola primária, experiências didáticas ricas em imagens, manipulação de objetos, respeitando as ordens lógica e psicológica prescritas pelos manuais pedagógicos da época, ministrando o ensino do próximo ao distante, do concreto ao abstrato, do global para o específico.

No estudo desenvolvido por Simião (2006, p.64) sobre a profissionalização docente em Mato Grosso, a autora faz referências às escolas isoladas urbanas:

Com a criação de novos municípios, passavam à categoria de urbanas as escolas rurais existentes no raio de três quilômetros da respectiva sede, e, em tal caso, os professores normalistas ali existentes eram promovidos a efetivos, ainda que sem concurso (Art. 254); mas nem sempre se contava com material humano disponível para atender as necessidades, conforme avaliou o professor Philogônio Corrêa.

A autora extrai essa referência do Relatório da Diretoria da Instrução Pública de Mato Grosso. O documento mencionado, também fonte do presente estudo, ao referir-se ao problema do ensino primário das pequenas cidades e vilas do interior de Mato Grosso, considera que o ensino das referidas escolas ainda não está de acordo com a Escola Nova devido à falta de formação profissional dos membros do magistério e à falta de intercâmbio de ideias entre os professores dos diversos Estados brasileiros (MATO GROSSO, 1943a).

\subsection{Vestígios da matemática da escola primária na década de 1940 em Mato Grosso}

São raras as escolas que guardam documentos escolares de tempos passados. A Escola Estadual Plácido de Castro, sediada na cidade de Diamantino - Mato Grosso é uma exceção por conservar em seus arquivos documentos valiosos dos tempos em que era uma das nove escolas urbanas do estado que ofertava ensino primário de três anos (um ano a mais do que as escolas isoladas rurais).

De conformidade com o Regulamento da Instrução Pública do Estado, denominam-se escolas urbanas também as que se localizam num raio de até três quilômetros da sede do município e têm um curso de três anos. São dezesseis as escolas urbanas e, exceptuadas quatro existentes na capital e três em Campo Grande, nove outras se acham situadas em Diamantino, Alto Araguaia, Mato Grosso, Araguaiana e Alto Madeira, extremos norte e leste do Estado. Em todas elas o processo de ensino é o mesmo adotado na capital (MATO GROSSO, 1943a, p.34).

De acordo com o Art. 1 do Regulamento da Instrução Pública (MATO GROSSO, 1927), ainda em vigor na década de 1940, o ensino primário público estava organizado em categorias: escolas isoladas rurais, escolas isoladas urbanas, escolas noturnas, escolas reunidas e grupos escolares.

A partir de documentos escolares localizados no Arquivo da Escola Estadual Plácido de Castro, da cidade de Diamantino (MT) - o "Registro Geral do Estabelecimento Escolar" da Escola Urbana Masculina e Feminina e o "Registro Geral do Estabelecimento Escolar do Externato Santa Teresinha", instituições sediadas naquele município, na década de 1940 -, foi possível verificar aspectos significativos do funcionamento das escolas como a composição da turma, número de alunos, 
faixa etária e principalmente o registro dos conteúdos programáticos, os "pontos" e a "base didática" vigentes na matemática escolar das escolas investigadas.

Os referidos documentos, preenchidos pela Professora Castorina $^{6}$, em 1941, e pela Professora Irmã Zélia, em 1943, contêm anotações das diferentes disciplinas escolares que compunham o currículo da escola primária. Os documentos contêm características do estabelecimento de ensino, o ponto diário do professor, nomes do professor responsável pela turma, inventário do mobiliário e do material escolar, lista de matrícula efetiva, informações da vida escolar do aluno, relação dos feriados escolares, frequência dos alunos, programa mensal das disciplinas escolares, promoções e reprovações de alunos, lista de alunos que não prestaram exames de admissão, registro de visitas oficiais ocorridas durante o ano letivo, termo de exame. Além do termo de abertura, os documentos apresentam o termo de encerramento, preenchido e assinado pela professora regente da sala de aula. No Termo de Abertura do Registro Geral da Escola Urbana Masculina, datado em 1 de março de 1941, a professora Castorina Sabo Mendes registra o nome da instituição escolar: "Escola Urbana Masculina", da cidade de Diamantino - MT.

O documento apresenta o programa do mês de março de 1941 e, dentre outras disciplinas do curso primário, a matemática escolar aparece nos registros com a denominação de Aritmética. Os conteúdos, denominados "pontos", são complementados com a sua forma de desenvolvimento, como as inúmeras menções à tabuada decorada.

Os registros acerca das turmas, turno e horário sugerem tratar-se de uma classe multisseriada. Um aspecto relevante do documento são os registros da página relativa à Base Didática do Programa de Ensino, indicando os livros didáticos utilizados nas disciplinas no ano letivo de 1941; dentre outros, a Aritmética Progressiva de Antonio Trajano, a Aritmética da FTD, os Exercícios de Cálculos da FTD e os Elementos de Tabuada de Povoas Pinheiro.

No documento relativo ao Externato Santa Terezinha, preenchido pela professora Irmã Zélia, que lecionou para as turmas do $1^{\circ}$ ano A, B, e C, seção feminina, no ano de 1943 , em relação à disciplina Aritmética, destacam-se os pontos trabalhados (números de 1 a 10) e o uso de grupos de objetos utilizados para a contagem, o exercício de cálculo com o uso de estampas e a resolução de problemas orais. Exercícios "intuitivos" e "práticos" são modalidades indicadas para a consecução dos "exercícios concretos", do "cálculo com o auxílio de estampas" e dos "problemas orais", que compunham o programa de Aritmética do mês de março.

Nos registros relativos ao mês de maio de 1943, constam anotações como o $2^{\circ}$ ponto de Geometria e o $30^{\circ}$ exercício, possíveis indicadores do uso do livro de Aritmética pelos alunos. Na mesma página do documento são detalhados os tipos de exercícios para as distintas disciplinas: desenho das faces do cubo, além dos lados e ângulos para a Geometria; a soma rápida, de 2 em 2 até 20, para a Aritmética.

$\mathrm{O}$ ensino intuitivo, um tema constante nos manuais de Lições de Coisas, nos compêndios de Pedagogia e nos relatórios oficiais da instrução pública da época, constitui-se como uma das importantes inovações pedagógicas da escola na metade do século XIX, momento de propagação da campanha universal em prol da criação e difusão da escola primária de ensino obrigatório, laica e gratuita para as classes populares e a consequente organização dos Sistemas Nacionais de Ensino, consubstanciando a educação escolar como função do Estado.

Dentre os registros dos documentos escolares analisados, os "pontos", as "formas de desenvolvimento" e a "referência no programa" atestam, em vários dos componentes curriculares, vestígios do ensino intuitivo, especialmente nas inúmeras menções às práticas de ensino através de "lições de coisas". Entretanto, na disciplina Aritmética, essa menção é muito reduzida, constando apenas um registro de "ensino intuitivo" e outro de "exercícios concretos e práticos". Ao que indicam tais registros, nas práticas de ensino da Aritmética predominavam as tradicionais formas de tratar os conteúdos: ler, copiar e decorar.

\section{Conclusão}

Ao longo da história, a matemática escolar da escola primária foi se constituindo enquanto disciplina escolar com uma trajetória marcada pelas reformas de ensino que prescreviam novas orientações às práticas escolares.

A Reforma Francisco Campos de 1931, dentre outras inovações, preocupou-se em modernizar a matemática escolar unificando disciplinas científicas, como a Aritmética e a Geometria, até então fragmentadas no currículo da escola primária. Desde o início da Primeira República o método intuitivo ganhava força nas escolas primárias brasileiras, em especial nos grupos escolares. Em 1930, auge do Movimento da Escola Nova no Brasil, advogava-se por um ensino mais intuitivo, por um conhecimento matemático mais contextualizado, mais voltado ao fazer cotidiano.

Entretanto, ao supervalorizar a ordem, a disciplina e a memorização, o ensino da matemática da escola primária prosseguia inspirado na "gramática geradora" dos saberes elementares necessários ao "ler, escrever e contar" e mantinha a disciplina fragmentada, como se pode observar nos Registros Gerais dos Estabelecimentos pela permanência no currículo da escola primária de duas disciplinas: Aritmética e Geometria.

As lições orais são uma constante nas aulas de Aritmética ao lado do ditado de números, o trio formado por exercícios, contas e problemas constituem o núcleo da lição escrita copiada do quadro-negro. Outra prova da permanência da memorização é a presença da tabuada, entre os demais

6 Segundo Souza (2006), a Professora Castorina, aos 99 anos, concedeu-lhe entrevista, contribuindo para sua dissertação de Mestrado. Contatada durante a realização do presente estudo, Souza informou que Castorina faleceu em 2008, aos 101 anos de idade. 
"pontos" do programa. Isso parece justificar, nos Registros Gerais do Estabelecimento, a menção da obra: Tabuadas e Elementos de Aritmética, de Povoas Pinheiro. Na edição de 1940, a obra traz informação sobre o quantitativo de dois milhões de exemplares vendidos.

A análise dos documentos escolares mostra que, apesar das reformas, movimentos e inovações didáticas, a matemática escolar da escola primária permaneceu, ainda na década de 1940, fragmentada e marcada pelos tradicionais códigos da cultura clássica, voltada ao cultivo dos espíritos.

\section{Referências}

BACKHEUSER, E. Como se ensina a Aritmética. Rio de Janeiro: Globo, 1946.

BITTENCOURT, C.M.F. Livro didático e conhecimento histórico: uma história do saber escolar. 1993. Tese (Doutorado em História) - Universidade de São Paulo. São Paulo, 1993.

CHERVEL. A. História das disciplinas escolares: reflexões sobre um campo de pesquisa. Teoria e Educação, v.2, p.177-229, 1990.

JULIA, D. A cultura escolar como objeto histórico. Rev. Bras. Hist. Educ., v.1, n.1, p.9-43, 2001.

MATO GROSSO. Regulamento da Instrução Pública da Escola Primária. Cuiabá, MT, 1927.

MATO GROSSO. Relatório da Diretoria Geral da Instrução Pública. Cuiabá, MT, 1943.

MATO GROSSO. Registro Geral do Estabelecimento. Escola Urbana Masculina. Arquivo da Escola Estadual Plácido de Castro, Diamantino, MT, 1941.

MATO GROSSO. Registro Geral do Estabelecimento. Externato Santa Terezinha - Arquivo da Escola Estadual Plácido de Castro,
Diamantino, MT, 1943.

OLIVEIRA, M.A.; RANZI, S.M.F. (Org.). História das disciplinas escolares no Brasil. Bragança Paulista: EDUSF, 2003.

PINTO, N.B. A Matemática da escola primária brasileira: tradição e modernização. Lisboa: Rev. Investig. Educ. Mat. Quadrante, v.17, n.1, p.27-45, 2008.

SILVA, M.C.L. A presença da matemática na formação do professor do ensino primário no estado de São Paulo, período de 1890 a 1930. Tese (Doutorado em Educação Matemática) Pontifícia Universidade Católica, São Paulo, 2008.

SIMIÃO, R.A.V. O processo de profissionalização docente em Mato Grosso (1930-1960). Cuiabá: EdUFMAT, 2006.

SOUZA, R.F.; FARIA FILHO, L.M. A contribuição dos estudos sobre grupos escolares para a renovação da história do ensino primário no Brasil. In: VIDAL, D.G. (Org.) Grupos escolares: cultura escolar primária e escolarização da infância no Brasil (1893-1971). Campinas: Mercado de Letras, 2006, p.21-56.

SOUZA, T.F.M. Alfabetização na escola primária em Diamantino-MT (1930 a 1970). 2006. Dissertação (Mestrado em Educação) - Universidade Federal de Mato Grosso, Cuiabá, 2006.

VALENTE, W.R. Uma história da matemática escolar no Brasil (1730-1930). São Paulo: Annablume/FAPESP, 1999a.

VALENTE, W.R. A matemática no ensino mútuo no Brasil. In: BASTOS, M.H. C.; FARIAS FILHO, L.M. A escola elementar no século XIX. O método monitorial/mútuo. Passo Fundo: Ediupf, 1999b, p.271-280.

VALENTE, W.R. Considerações sobre a matemática escolar numa abordagem histórica. Cad. Hist. Educ., v.3, p.77-82, 2004.

VIDAL, D.G. (Org.). Grupos escolares: cultura escolar primária e escolarização da infância no Brasil (1893-1971). Campinas: Mercado de Letras, 2006. 